\title{
Basic Research on the Biology of Meta-tetra(hydroxyphenyl) Chlorin for Photodynamic Therapy in Gynaecology: Somatic Genotoxicity Assayed with Drosophila melanogaster
}

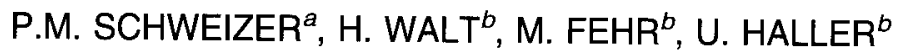 \\ a'Institute for Medical Radiobiology, University of Zürich and Paul Scherrer Institute, CH-8029 Zürich, Switzerland \\ ${ }^{b}$ Research Division of Gynaecology, Department of Gynaecology and Obstetrics, University Hospital, CH-8091 Zürich, \\ Switzerland \\ Correspondence to: P.M. Schweizer, Institute for Medical Radiobiology of the University of Zürich and the Paul Scherrer \\ Institute, August Forel Str. 7, CH-8029 Zürich, Switzerland \\ Received 15 June 1996; accepted in final form 31 January 1997
}

\begin{abstract}
The well-established SMART test, a somatic mutation and recombination assay of Drosophila, was applied to assess the possible genotoxicity of sublethal meta-tetra(hydroxyphenyl) chlorin (mTHPC) photodynamic therapy (PDT) to clonogenic cells in situ. The SMART assay monitors the loss of heterozygosity $(\mathrm{LOH})$ at selected cell-marker loci in clonogenic cells of the larval wing primordia. No evidence of genotoxicity was observed under conditions that killed between 38 and $86 \%$ of the exposed test larvae. Since the SMART assay is based on the oral uptake of the suspected genotoxic agent, the uptake kinetics of mTHPC by the assay's specific target cells must be known. Therefore, relevant studies are being carried out at present in order to draw final conclusions from this negative test result for genotoxicity.
\end{abstract}

\section{INTRODUCTION}

Photodynamic tumour therapy (PDT) is based on the light-induced activation of photoreactive drugs, thus generating highly reactive oxygen species that are toxic to the cells. Local restriction of photodynamic impacts to the target tissue is achieved by systemic or local administration of the photodynamic agents and, subsequently, strictly limited illumination of the target tissue area. The development of new photosensitizers is regularly followed by extended preclinical studies. Such studies are now being carried out on the bioreactivity of second-generation photosensitizers. Extensive testing of chlorins such as meta-tetra(hydroxyphenyl) chlorin (mTHPC) by in vitro experiments that analysed the dark toxicity and the DNA modifications of tumour cells found neither of these effects (1). The authors were also interested in the potential risk of genotoxicity and somatic mutagenicity of photosensitizers. In PDT, light scattering will inevitably leave a marginal zone of subcytotoxically treated cells. These could potentially constitute a source of late complications arising from DNA alterations where the cell impact was sublethal. Activated oxygen, referred to as singlet oxygen, is a DNAdamaging agent (2). Its relatively short lifetime in solution, between micro- and milliseconds (3), limits its interaction with biomolecules to the vicinity of the photoreagents from which it is produced. The risks of mutagenic effects from PDT will depend largely on the spatial distribution of photoreactive agents within the cytoplasmic and nuclear compartments of the cells (3-5). Several studies have actually demonstrated the DNA-modifying activity of photo-oxidative reactions. Following photooxidation by haematoporphyrin derivatives, DNA alterations such as alkali-labile sites (6), single- and double-strand breaks (7-10), induction of sister chromatid exchanges (SCE) $(11,12)$ and chromosome aberrations were observed (13). Most interestingly, the inhibition of DNA repair functions by photooxidative reactions has also been documented 
recently $(10,14)$. Consequently, mutagenic and clastogenic effects in subcytotoxically affected cells could also be produced indirectly as a consequence of an impaired capacity of the metabolism to maintain DNA integrity (10). For the present study of the genotoxicity of $\mathrm{mTHPC}$ and its photo-oxidative reaction, the well-established and sensitive somatic mutation and recombination assay of Drosophila melanogaster known as SMART was chosen (15-17). This test monitors the consequences of the loss of heterozygosity (LOH) due to a broad spectrum of mutational events such as point mutations, deletions, homologue recombination, chromosome loss and non-disjunction as well as gene conversion (15). Loss of heterozygosity is recognized as an important cause of tumour-suppressor neoplasia mediated by gene loss in humans (16). In the fruit fly $D$. melanogaster, which is heterozygous for appropriate recessive mutations that alter the morphology of the cuticle in a cell-autonomous fashion, the loss of heterozygosity in somatic cell lineages becomes visible as spots of mutant characters (genetic mosaics) on the body surface of the adult flies.

The authors addressed the question as to whether a subcytotoxic PDT treatment with mTHPC that killed $38-86 \%$ of the larvae would yield an enhanced frequency of LOH-mediated genetic mosaics among the survivors compared to untreated controls.

\section{MATERIALS AND METHODS}

The SMART test protocol has been described comprehensively by Graf et al (15). The test is based on feeding potential mutagens to larvae of the fruit fly D. melanogaster that are transheterozygous for the recessive wing-cell marker mutations multiple wing hairs (mwh) and flare (flr). The induced loss of heterozygosity at either or both of the loci in clonogenic cells is expressed in the resulting clones as mutant spots on the phenotypically wildtype wing surface of the hatched adults. Homologous recombination proximal to the marker loci gives rise to mwh/flr twin spots (Fig. 1). Single spots expressing the distal marker mwh result primarily from the recombination between the two marker positions mwh and flr, from terminal deletions covering the distal marker mwh or from mutation of the wild-type allele. Single spots expressing the phenotype of the proximal marker flr can

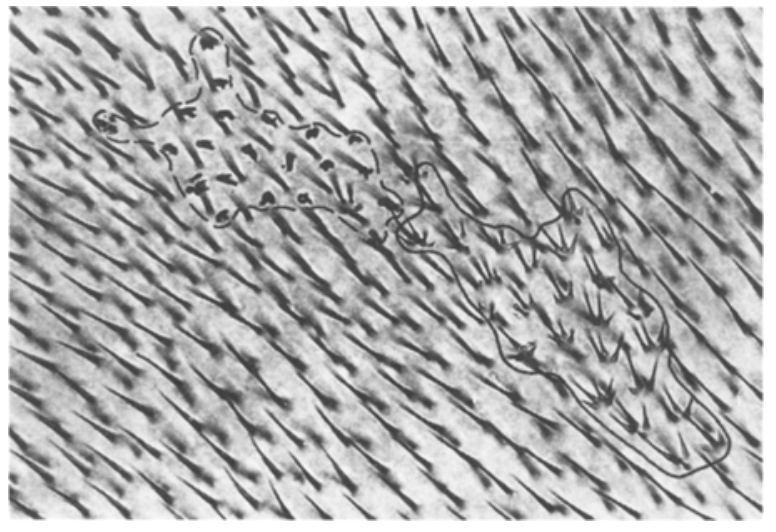

Fig. 1. Microscopic view of a wing area from a SMART assay fly displaying representative examples of clonal expression of the recessive cell-marker mutations multiple wing hairs (mwh) and flare (flr) following loss of heterozygosity $(\mathrm{LOH})$ in wing precursor cells of a fly heterozygous at the respective loci.

result from double recombination proximal and distal to the respective locus flr, lethality of one of the twin products of a proximal recombination event, gene mutation or gene conversion (15).

$\mathrm{F}_{1}$ larvae from crosses of the homozygous $\mathrm{mwh} / \mathrm{mwh}$ strain carrying the visible recessive mutation multiple wing hairs (mwh $3-0.00$ ) and of the balanced strain flr3/TM3, ri pp e bx34 Ser, carrying the wing-hair mutation flare (flr 3-38.8) (15) were chronically exposed to the photosensitizer mTHPC (Foscan ${ }^{\circledR}$, Scotia Pharmaceuticals Ltd, Guildford, UK) by being fed up to $45 \mathrm{mg} \mathrm{mTHPC}$ per $\mathrm{ml}$ of instant food. After an incubation period of $64 \mathrm{~h}(84 \mathrm{~h}$ after egg laying), the larvae were exposed to laser illumination at $652 \mathrm{~nm} 8.45 \mathrm{~J} \mathrm{~cm}^{-2}$ for $16 \mathrm{~min}$. The irradiation was carried out using either an argon ion-pumped dye laser (Coherent Innova 310 and CR 599, GMP, Switzerland) or a diode laser (Applied Optronics, USA). The lethality rate of the larvae in several test tubes pooled for this study was between 38 and $86 \%$. The lethality rate was recorded $24-48 \mathrm{~h}$ after exposure to the laser illumination when the surviving larvae underwent pupation. In additional series, the larvae were exposed to Ringer solvent alone, to laser illumination alone, to mTHPC incubation in the dark and to $4 \mathrm{~Gy}$ of X-rays ( $84 \mathrm{~h}$ after egg laying, $100 \mathrm{kVp}$

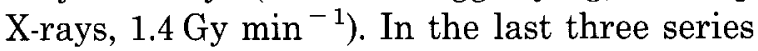
mentioned above, the survival of the larvae was not affected compared to the series subject to exposure to Ringer's solvent alone. X-rays of $4 \mathrm{~Gy}$ were applied to demonstrate the operation of the assay. The X-ray dose was monitored by a PTW-SN4 dosimeter. After 
metamorphosis, the hatched adults were collected and the wings were examined for mutant spots at a magnification of $400 \times$ following the method and criteria of Graf et al (15).

The statistical validation of the data obtained in this study was based on the computer-assisted program LIMIT for the routine evaluation of the Drosophila wing-spot test SMART (17). This program validates the mosaic frequency in control and treated series with respect to a null hypothesis $\mathrm{H}(\mathrm{O})$ postulating no difference between a control and a treated series, and the alternative hypothesis $\mathrm{H}(\mathrm{A})$ that assumes an a priori mosaic frequency $\mathrm{m}$ times the spontaneous level. Acceptance or rejection of either hypothesis is based on the conditional binomial distribution.

\section{RESULTS}

Figure 1 illustrates representative examples of clonal expressions in the wing margin of the recessive cell-marker mutations multiple wing hairs (mwh) and flare (flr) following radiationinduced $\mathrm{LOH}$ in the wing precursor cells of the larvae. Table 1 summarizes the total number of wings analysed and the scores of mosaic spots per wing in control and treated series, as well as the diagnosis for genotoxicity according to the LIMIT statistics program of the SMART genotoxicity assay (16). The particularly relevant clone classes are the large mwh single spots identifying LOH due primarily to distal mitotic recombination, terminal deletions and gene mutations, and the $\mathrm{wmh} / \mathrm{flr}$ twin spots identifying the homologous recombination proximal to the marker loci. Small single spots result from $\mathrm{LOH}$ in development later than $84 \mathrm{~h}$ after egg laying (20). No effects on their frequency could be expected under the present treatment conditions. Single flr spots result from double recombination proximal and distal to this marker gene. Their spontaneous frequency is therefore very low (18) and will be affected only by strong recombinogenic agents. It is evident from the data compiled in Table 1 that the SMART assay is sensitive enough to detect the somatic mutagenicity and recombinogenicity associated with a moderate X-ray dose of $4 \mathrm{~Gy}$ and, according to the authors' previous study (19), even with X-ray doses as low as $1 \mathrm{cGy}$. Conversely, neither of the other treatments, eg laser illumination alone, mTHPC dark toxicity or PDT treatment (mTHPC+laser), led to a recognizable enhancement of spot frequencies. $H(0)$ was accepted at a significance level of $2 a=0.05$ in all these latter series and with respect to all indicators.

\section{DISCUSSION}

The biological effects of PDT are complex and their comprehensive elucidation requires diverse systematic studies. Every photosensitizer reacts differently and its targets are mainly subcellular organelles within the cytoplasm. To establish PDT effects in greater detail, the dark toxicity and reactivity of mTHPC in vitro in human tumour cells was studied using two test systems, namely the colony-forming test and the cell-viability test $(21,22)$. These tests clearly demonstrated the effectiveness of mTHPC as a somatic photosensitizing substance. The decision to test the genotoxicity of PDT with a relevant assay was a logical consequence of the earlier analysis. The Drosophila SMART assay is well established in terms of toxicology and cross examinations of the effectiveness of drugs in the SMART test, and other established tests for carcinogenicity reveal an excellent correlation (23). The presented data yielded no evidence of a genotoxic effect from PDT treatment mediated by mTHPC. Considering that the PDT treatment caused substantial lethality among the exposed larvae (38-86\%), the possibility of insufficient uptake of mTHPC by the larvae can be excluded. However, the timedependent and spatial pharmacokinetics of mTHPC has not yet been studied in the specific target tissue of the SMART assay. This study is currently in progress and its outcome is needed to draw final conclusions about the non-genotoxicity of PD'T mediated by mTHPC in the SMART assay. A fluorescence analysis of the mTHPC uptake is being used in addition to cell pathology methods to identify necrotic and/or apoptotic cell decay after PDT treatment. Since the SMART assay has proved itself capable of identifying the genotoxic activity of a large variety of agents via oral application (23), the authors' preliminary inclination is to suggest that the failure to observe genotoxic activity following the reported mTHPC PDT treatment is not merely a consequence of an insufficient uptake. On the basis of these results, the authors are optimistic that 


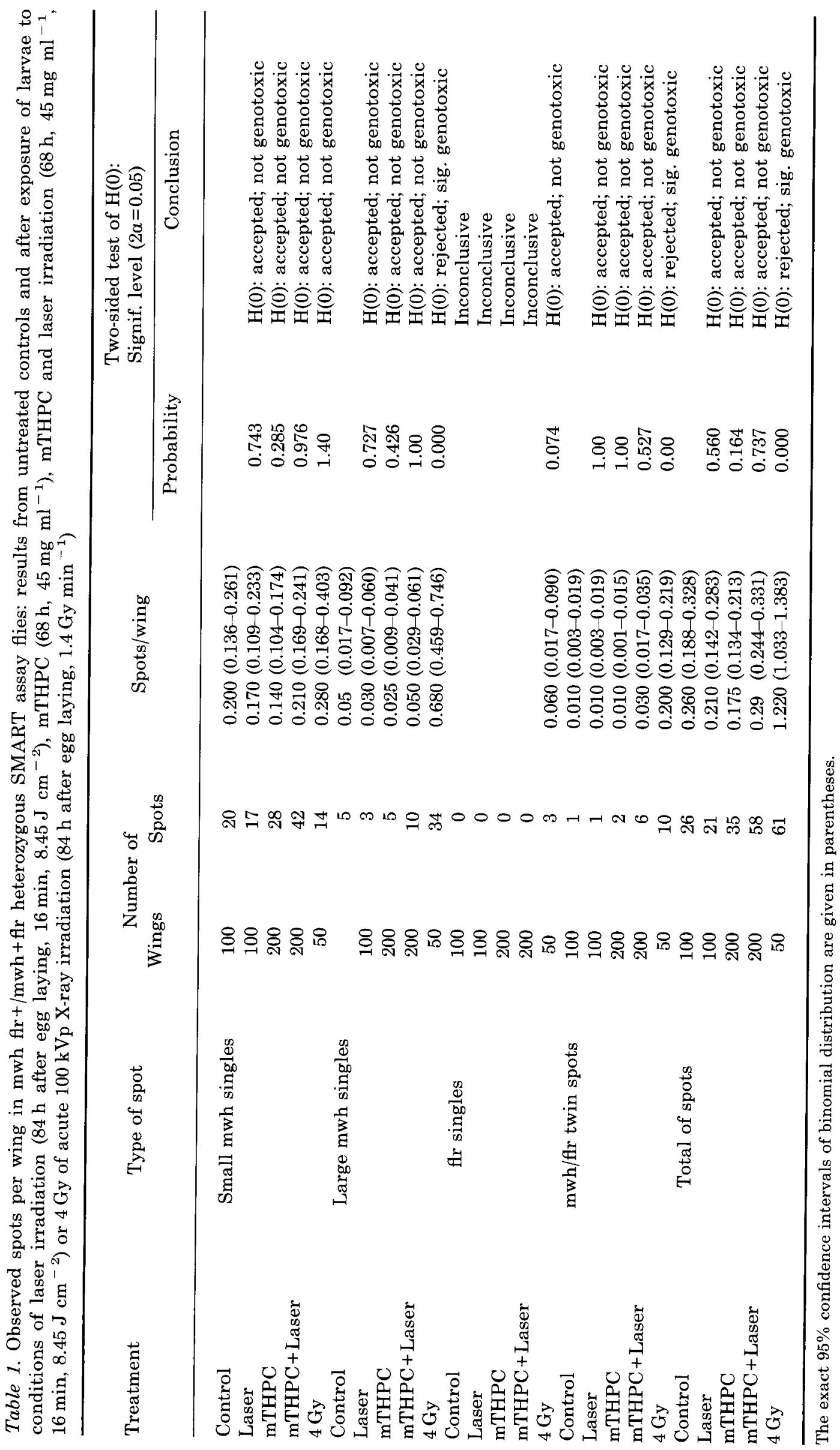


D. melanogaster has the potential for being used in additional preclinical studies in PDT. Since various forms of malignant tumour also occur in this insect that is so convenient to study, the authors have started a series of experiments to investigate the action of PDT on neoplasms using this model.

\section{ACKNOWLEDGEMENTS}

The authors thank Diana Dobler-Girdziunaite, Brigitte Jentsch and Ritva Haider for their excellent technical help, and Pam Kessler and Richard Michel for assistance in preparing the manuscript. The authors also acknowledge Dr H. Frei of the Institute of Toxicology at the Swiss Federal Institute of Technology and the University of Zürich for his support in applying the SMART statistical method.

\section{REFERENCES}

1 Hornung R, Jentsch B, Crompton NEA, Haller U, Walt $\mathrm{H}$. In vitro effects and localisation of the photosensitizers $\mathrm{m}$-THPC and $\mathrm{m}$-THPC MD on carcinoma cells of the human breast (MCF-7) and Chinese hamster fibroblasts (V-79). Lasers Surg Med 1997, 20:443-50

2 Decuyper-Debergh D, Piette J, Van deVorst A. Singlet oxygen-induced mutations in M3 lacZ phage DNA. EMBO J 1987, 6:3155-61

3 Merkel PB, Kearns DR. Radiationless decay of singlet molecular oxygen in solution. An experimental and theoretical study of electronic and vibrational energy transfer. $J$ Am Chem Soc 1972, 94:7244-53

4 deMol HJ, Beijersbergen GMJ, Mohn GR, Glickman BW, van Kleef PM. On the involvement of singlet oxygen in mutation induction by methoxypsoralen and UVA irradiation in E. coli. Mutat Res 1981, 82:23-30

5 Devasagayan TPA, Steenken S, Obendorf WSW, Schulz WA, Sies H. Formation of 8-hydroxy(deoxy)guanosin and generation of strand breaks at the guanine residue by singlet oxygen. Biochemistry 1991, 36:6282-9

6 Gomer CJ. DNA damage and repair in CHO cells following haematoporphyrin photoradiation. Cancer Lett 1980, 11:161-7

7 Moan J, Waksvik H, Christensen T. DNA single-strand breaks and sister chromatide exchanges induced by treatment with haematoporphyrin and light or by X-rays in human NHiK3025 cells. Cancer Res 1980, 40:2915-8

8 Fiel RJ, Datta-Gupta N, Mark EH, Howard JC. Induction of DNA damage by porphyrin photosensitization. Cancer Res 1981, 41:3543-5

9 Epe B, Pflaum M, Boiteux S. DNA damage induced by photosensitizers in cellular and cell-free systems. Mutat Res 1993, 299:135-45

10 Penning LC, Lagerberg JWM, VanDierendonck, Cornelisse CJ, Dubbelman TMAR, VanStevenick J.
The role of DNA damage and inhibition of poly(ADPribosyl)ation in loss of clonogenicity of murine L-fibroblasts, caused by photodynamically induced oxydative stress. Cancer Res 1994, 54:5557-61

11 Christensen T, Moan J, McGhie JB, Waksvik H, Stigum H. Studies of $\mathrm{HpD}$ chemical composition and in vitro photosensitization. In: Kessel D, Dougherty TJ (eds) Porphyrin Workshop. New York: Plenum, 1983:151-64

12 Gomer CJ, Rucker N, Banerjee A, Benedict WF. Comparison of mutagenicity and induction of sister chromatid exchange in Chinese hamster cells exposed to hematoporphyrin derivative, photoradiation, ionizing radiation, or ultraviolet radiation. Cancer Res 1983, 43:2622-7

13 Evensen JF, Moan J. Photodynamic action and chromosomal damage: A comparison of hematoporphyrin derivative $(\mathrm{HpD})$ and light with X-irradiation. $\mathrm{Br} J$ Cancer 1982, 45:465-82

14 Boegheim JPJ, Dubbelman TMAR, Mullerdens LHF. Photodynamic effects of heamtoporphyrin derivative on DNA repair in murine 1929 -fibroblasts. Biochem $J$ 1987, 244:711-5

15 Graf U, Würgler FE, Katz AJ, Frei H, Juon H, Hall CB, Kale PG. Somatic mutation- and recombination-test in Drosophila melanogaster. Environ Mutagen 1984, 6:153-88

16 Lasko D, Cavenee W. Loss of constitutional heterozygosity in human cancer. Annu Rev Genet 1991, 25:281-314

17 Frei H, Würgler FE. Statistical methods to decide whether mutagenicity test data from Drosophila assays indicate a positive, negative, or inconclusive result. Mutat Res 1988, 203:297-308

18 Hall EJ. Radiobiology for the Radiologist, 4th edn. Philadelphia: J.B. Lippincott Company, 1994

19 Schweizer P. Linear dose-response relationship and no inverse dose-rate effect observed for low X-ray dose-induced mitotic recombination in Drosophila melanogaster. Int $J$ Radiat Biol 1995, 67:303-13

20 Garcia-Bellido A, Merriam J. Parameters of wing imaginal disc development of Drosophila melanogaster. Development Biol 1971, 24:61-87

21 Koechli OR, Schaerer GN, Schenk V, Haller U, Walt H. Assessment of effects of photosensitizers on cytotoxicity and phtotodynamic therapy in human breast cancer cell cultures. Arch Gynecol Obstet 1995, 256:167-76

22 Dobler-Girdziunaite D, Burkard W, Haller U, Larsson B, Waet H. Kombinierte Anwendung der photodynamischen Therapie mit ionisierenden Strahlen bei Mammakarzinomzellen in vitro. Strahlenther Onkol 1995, 171:622-9

23 Vogel EM, Nivard JM. Performance of 181 chemicals in a Drosophila assay predominantly monitoring intrachromosomal mitotic recombination. Mutagenesis 1993, 8:357-81

Key words: Photodynamic therapy; Meso-tetra(hydroxyphenyl) chlorin (mTHPC); Genotoxicity; SMART test; Drosophila melanogaster 